\title{
$15.3 \%$ efficiency all-small-molecule organic solar cells enabled by symmetric phenyl substitution
}

\author{
Jinzhao Qin ${ }^{1,2}$, Cunbin An ${ }^{1 *}$, Jianqi Zhang ${ }^{2,3 *}$, Kangqiao Ma ${ }^{1}$, Yang Yang ${ }^{2,3}$, Tao Zhang ${ }^{1}$, Sunsun $\mathrm{Li}^{1}$, \\ Kaihu Xian ${ }^{1,2}$, Yong Cui ${ }^{1}$, Yabing Tang ${ }^{5}$, Wei Ma ${ }^{5}$, Huifeng Yao ${ }^{1}$, Shaoqing Zhang ${ }^{4}$, Bowei Xu ${ }^{1}$, \\ Chang $\mathrm{He}^{1 *}$ and Jianhui $\mathrm{Hou}^{1,2^{*}}$
}

\begin{abstract}
Synergistic optimization of donor-acceptor blend morphologyis a hurdle in the path of realizing efficient non-fullerene small-molecule organic solar cells (NFSMOSCs) due to the anisotropic conjugated backbones of both donor and acceptor. Therefore, developing a facile molecular design strategy to effectively regulate the crystalline properties of photoactive materials, and thus, enable the optimization of blend morphology is of vital importance. In this study, a new donor molecule B1, comprising phenyl-substituted benzodithiophene (BDT) central unit, exhibits strong interaction with the non-fullerene acceptor $\mathrm{BO}-4 \mathrm{Cl}$ in comparison with its corresponding thiophene-substituted BDT-based material, $B T R$. As a result, the $B 1$ is affected and induced from an edgeon to a face-on orientation by the acceptor, while the BTR and the acceptor behave individually for the similar molecular orientation in pristine and blend films according to grazing incidence wide angle $\mathrm{X}$-ray scattering results. It means the donor-acceptor blend morphology is synergistically optimized in the $\mathrm{B} 1$ system, and the $\mathrm{B} 1: \mathrm{BO}-4 \mathrm{Cl}-\mathrm{based}$ devices achieve an outstanding power conversion efficiency (PCE) of 15.3\%, further certified to be $\mathbf{1 5 . 1 \%}$ by the National Institute of Metrology, China. Our results demonstrate a simple and effective strategy to improve the crystalline properties of the donor molecule as well as synergistically optimize the morphology of the all-small-molecule system, leading to the high-performance NFSM-OSCs.
\end{abstract}

Keywords: organic solar cells, all-small-molecule, non-fullerene, crystallinity, intermolecular interaction

\section{INTRODUCTION}

Non-fullerene (NF) fused-ring acceptors have been frequently utilized to achieve remarkable development for the polymer-based organic solar cells (OSCs) via various methods of morphology control and interface engineering [1-3]. Apart from the conjugated polymers, small molecules (SMs) have also proved to be excellent candidates for the active layers with advantages of well-defined molecular structures and low batch-to-batch variations (an attractive aspect with regard to commercialization). Compared with polymer-based OSC, NFSM-OSC is more suitable as a research model device, which can more easily establish clear relationships between the structure and performance [4-8]. However, the power conversion efficiencies (PCEs) of current state-of-the-art NFSM-OSCs are still much lower than that of polymer-based OSCs because small molecules cannot form pre-aggregation in solution like most high-performance polymers [9-11], and have similar acceptor-donor-acceptor (A-D-A) skeleton structures with high efficiency non-fullerene acceptors, making it difficult to regulate their morphology [12-21]. To date, though considerable efforts have been made in the research of NF acceptors and a number of high-performing materials have been reported, the study on small molecule donors for efficient NFSM-OSCs is relatively lagging $[1,22-26]$. Thus, it is imperative to develop high-performance small molecule donors and get insight into the molecular design of donor compound, and its effect on the blend morphology and device per-

\footnotetext{
${ }^{1}$ State Key Laboratory of Polymer Physics and Chemistry, Institute of Chemistry, Chinese Academy of Sciences, Beijing 100190, China

${ }^{2}$ University of Chinese Academy of Sciences, Beijing 100049, China

${ }^{3}$ Key Laboratory of Nanosystem and Hierarchical Fabrication, National Center for Nanoscience and Technology, Beijing 100190, China

${ }^{4}$ School of Chemistry and Biology Engineering, University of Science and Technology Beijing, Beijing 100083, China

${ }^{5}$ State Key Laboratory for Mechanical Behavior of Materials, Xi'an Jiaotong University, Xi'an 710049, China

*Corresponding authors (emails: hjhzlz@iccas.ac.cn (Hou J); hechang@iccas.ac.cn (He C); ancunbin@iccas.ac.cn (An C); zhangjq@nanoctr.cn (Zhang $\mathrm{J}))$
} 
formance.

In recent studies, notable progress has been made in donor molecule design to develop small-molecule donors for NFSM-OSCs. One of them is enlarging the coplanar core and extending the conjugation length to regulate the donor structure and render NFSM-OSCs optimized hierarchical morphologies to obtain certified PCE over $14 \%$ [27]. The other is halogenation, which means to introduce fluorine, chlorine or bromine atoms to the specific positions of some representative units to adjust the energy levels and crystalline properties of the small molecule donor. On the basis of this strategy, several small molecular donors, such as benzodithiophene- $\mathrm{Cl}$ (BTR-Cl), BSFTR and BTEC-2F have been developed (see Table 1) and the corresponding OSCs achieve PCEs over $13 \%$ when blended with the small molecule acceptor Y6 [28-30]. It is well known that variations in morphology induced by the changes in crystallinity and molecular orientation have a significant impact on the performance of OSCs [31-34]. It is worth pointing out that the crystallization characteristics of the donor materials in these studies have all been regulated, and we infer that the improved crystallinity of donor compound may lead to stronger interactions between the donor and the NF acceptor materials to realize synergistic optimization of the morphology and benefit the high-performance NFSMOSCs. However, the research on the relationship between synergistic optimization morphology via fine-modulation of crystalline properties and device performance is still lack.

Thiophene substituted benzodithiophene (BDT) units have been widely used in the molecular design of organic photovoltaic materials because of their excellent charge transfer characteristics [35]. However, single-bonded thiophene units easily twist and have multiple conformations, which is not conducive to the improvement of crystallinity, as materials with symmetrical side groups may contribute to higher crystallinity $[36,37]$. In this study, a new two dimensional (2D)-conjugated donor, B1
(Fig. 1a), was designed and synthesized by using the symmetric phenyl units as the side group of the central backbone. The reported molecule BTR [38] with thiophene-substituted side group was selected as reference donor, and the solar cells were prepared with the same $\mathrm{NF}$ acceptor, $\mathrm{BO}-4 \mathrm{Cl}$ (Fig. 2a) [3]. Interestingly, simply changing the substituted side group from thiophene to phenyl units enhanced the molecular conformation stability, and therefore the crystallinity and electronic properties were greatly improved. The all-small-molecule OSCs obtained by pairing $\mathrm{B} 1$ with $\mathrm{BO}-4 \mathrm{Cl}$ exhibited a PCE of $15.3 \%$ (certified at $15.1 \%$ ), which was $35 \%$ higher than that of BTR:BO-4Cl (11.3\%). This is the highest PCE among NFSM-OSCs reported so far, which suggests symmetric conjugated side group substitution could be a promising method for preparing high performance OSCs.

\section{EXPERIMENTAL SECTION}

\section{Instruments}

${ }^{1} \mathrm{H}$ NMR and ${ }^{13} \mathrm{C}$ NMR spectra were recorded on a Bruker AVANCE 400 and $75 \mathrm{MHz}$ NMR spectrometer at room temperature. Absorption spectra of the materials were measured on a Hitachi UH5300 spectrophotometer. Cyclic voltammogram (CV) measurements were conducted on a CHI650D electrochemical workstation using glassy carbon as the working electrode, $\mathrm{Pt}$ wire as the counter electrode, and $\mathrm{Ag} / \mathrm{AgCl}$ as the reference electrode in a $0.1 \mathrm{~mol} \mathrm{~L}^{-1}$ tetrabutylammonium hexafluorophosphate $\left(\mathrm{Bu}_{4} \mathrm{NPF}_{6}\right)$ acetonitrile solution. The atomic force microscopy (AFM) height and phase images were acquired on a Bruker Nanoscope $\mathrm{V}$ AF microscope in tapping mode in the air. The external quantum efficiency (EQE) data were obtained by using the solar-cell spectralresponse measurement system (QE-R, Enlitech). The transmission electronic microscopy (TEM) images were obtained on a Tecnai G2 F20 U-TWIN TEM instrument. The grazing incidence wide angle X-ray scattering (GIWAXS) data were obtained on a XEUSS SAXS/WAXS

Table 1 Photovoltaic data for recent reported high-efficency NFSM-OSCs (PCE > 13\%)

\begin{tabular}{|c|c|c|c|c|c|c|c|}
\hline Donor & Acceptor & $V_{\mathrm{oc}}(\mathrm{V})$ & $J_{\mathrm{sc}}\left(\mathrm{mA} \mathrm{cm}^{-2}\right)$ & $\mathrm{FF}$ & PCE (\%) & Certified PCE (\%) & Ref. \\
\hline BTR & $\mathrm{NITI}+\mathrm{PC}_{71} \mathrm{BM}$ & 0.94 & 19.50 & 0.74 & 13.6 & 12.9 & [19] \\
\hline BTR-Cl & Y6 & 0.86 & 24.17 & 0.66 & 13.6 & 13.0 & [28] \\
\hline BSFTR & Y6 & 0.85 & 23.16 & 0.70 & 13.7 & 13.6 & [29] \\
\hline ZR1 & Y6 & 0.86 & 24.34 & 0.68 & 14.3 & 14.1 & [27] \\
\hline BTEC-2F & Y6 & 0.85 & 21.55 & 0.72 & 13.3 & - & [30] \\
\hline B1 & $\mathrm{BO}-4 \mathrm{Cl}$ & 0.83 & 25.27 & 0.73 & 15.3 & 15.1 & This work \\
\hline
\end{tabular}



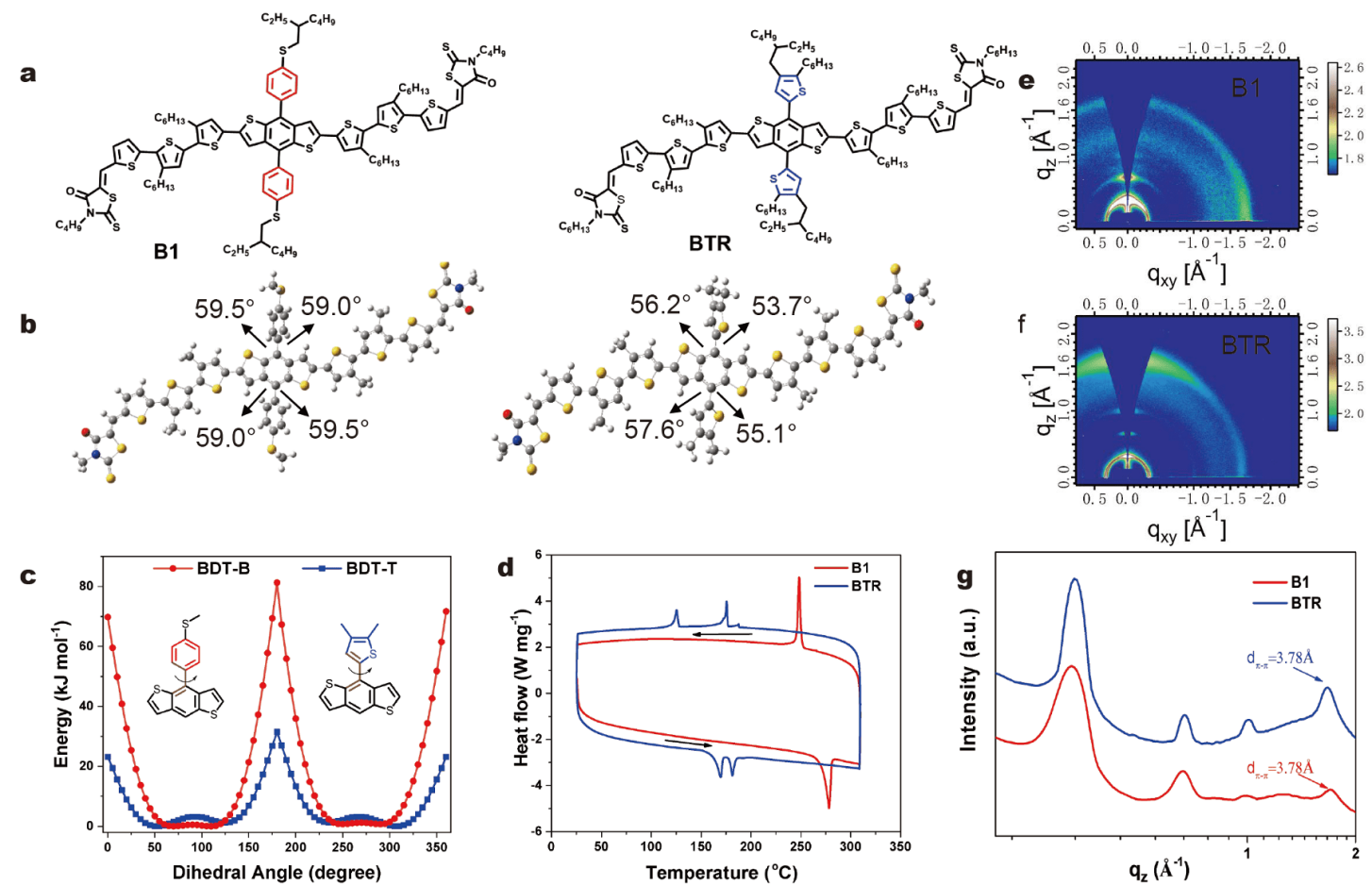

Figure 1 (a) Chemical structures of the small moleculars donors B1 and BTR. (b) Optimized molecular structures of B1 and BTR obtained from the DFT-based theoretical calculations. (c) The total energy scans dependent on dihedral angles for model compounds BDT-B and BDT-T. (d) DSC traces of B1 and BTR in nitrogen at a rate of $10^{\circ} \mathrm{C} \mathrm{min}{ }^{-1}$. 2D GIWAXS pattern of the neat (e) B1 and (f) BTR films. (g) Extracted 1D profiles along the OOP direction of the neat $\mathrm{B} 1$ and BTR films.

a
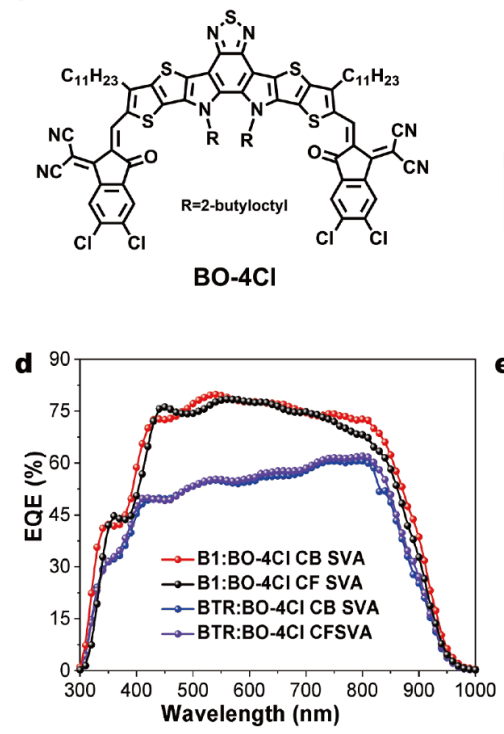

b
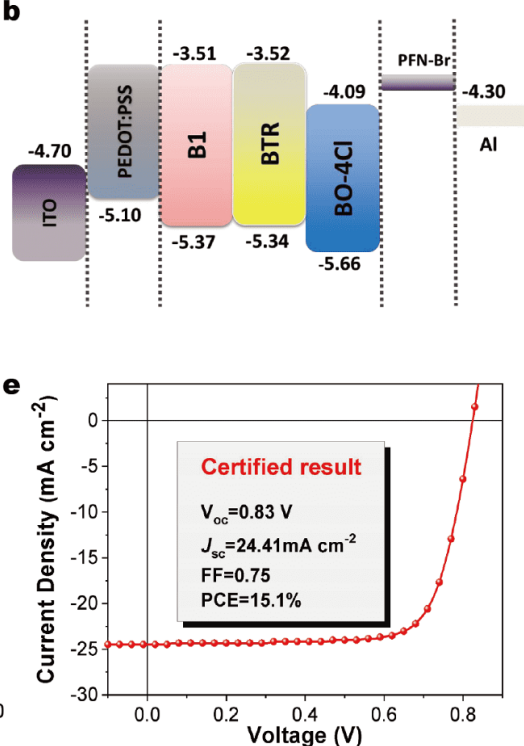

C

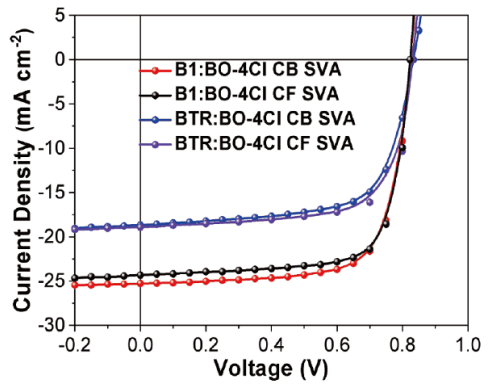

$\mathbf{f}$

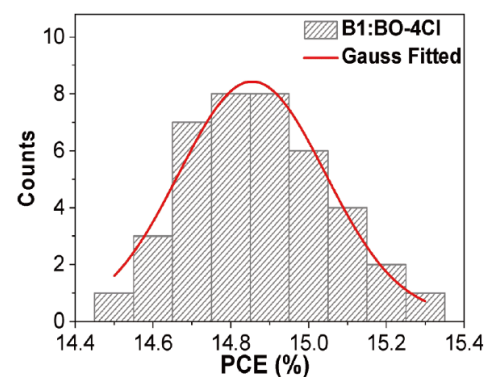

Figure 2 (a) Chemical structure of BO-4Cl. (b) Energy level diagrams. (c) $J-V$ curves of the BTR:BO-4Cl- and B1:BO-4Cl-based devices. (d) EQE curves of the BTR:BO-4Cl- and B1:BO-4Cl-based devices. (e) $J-V$ curve of the device measured by the NIM, China. (f) The statistical diagram of PCEs for 40 individual B1:BO-4Cl-based devices with CB SVA treatment. 
SYSTEM (XENOCS, FRANCE) at the National Center for Nanoscience and Technology (NCNST, Beijing). The current density-voltage characteristics $(J-V)$ were measured with a Keithley 2400 Source Measure unit under $100 \mathrm{~mW} \mathrm{~cm}^{-2}$ standard AM 1.5G light.

\section{Solar cell device fabrication}

The photovoltaic devices were fabricated with a conventional structure of ITO/PEDOT:PSS/BHJ/PFN-Br/Al. The fabrication process was performed under the following procedures: the ITO was ultrasonically cleaned with successive applications of detergent, deionized water, acetone and isopropanol twice. After drying, the substrates were treated with UV-ozone for $20 \mathrm{~min}$, and then a $20 \mathrm{~nm}$ layer of poly(3,4-ethylenedioxythiophene):poly (styrenesulfonate)(PEDOT:PSS)(Heraeus Materials,4083) was spin-coated onto the indium tin oxide (ITO), and the ITO substrates were dried in an oven at $150^{\circ} \mathrm{C}$ for $15 \mathrm{~min}$. The donor and acceptor were dissolved in chloroform (CF) with a total concentration of $20 \mathrm{mg} \mathrm{mL}^{-1}$ (D/A weight ratio of 1:1) and then stirred at room temperature for at least $6 \mathrm{~h}$. After the active layer solutions were spincoated at $3000 \mathrm{rpm}$ for $30 \mathrm{~s}$ to obtain a film thickness about $100 \mathrm{~nm}$. Then the devices were treated with solvent vapor annealing (SVA) in a $60 \mathrm{~mm}$ diameter dish. And then PFN-Br methanol solution $\left(0.5 \mathrm{mg} \mathrm{mL}^{-1}\right)$ was spincoated at $3000 \mathrm{rpm}$ on the active layer. Finally, about 100nm-thick Al was deposited onto the active layer under vacuum at a pressure of $3 \times 10^{-4} \mathrm{~Pa}$, giving an effective area of $3.7 \mathrm{~mm}^{2}$. After the spin-coating of PEDOT:PSS, next steps were carried out in the glovebox of nitrogen atmosphere. The $J-V$ tests were carried out using the solar simulator (SS-F5-3A, Enlitech) in glove box. The radiative intensity (AM $1.5 \mathrm{G}$ spectrum, $100 \mathrm{~mW} \mathrm{~cm}^{-2}$ ) was calibrated by the standard silicon solar cell.

\section{RESULTS AND DISCUSSION}

Since B1 and BTR possess the same conjugated backbone structure (shown in Fig. 1a), the synthesis of B1 is similar to the previously reported method $[39,40]$. The synthesis route and detailed characterizations of B1 were shown in Supplementary information (SI, Scheme S1, Figs S1-S4). To investigate the molecular geometries of B1 and BTR, we performed density functional theory (DFT) analysis with the B3LYP (6-31G (d, p)) basis set. As shown in Fig. 1b, both donor compounds display nearly planar skeletons. The dihedral angle between the BDT central core and the phenyl/thienyl substituent is $59^{\circ} / 53^{\circ}$. Furthermore, the rotational energy barriers of B1 and BTR were compared using the potential energy surface scan by
DFT. The twisting barrier in BDT-T is $30 \mathrm{~kJ} \mathrm{~mol}^{-1}$, whereas that of the BDT-B unit reaches $80 \mathrm{~kJ} \mathrm{~mol}^{-1}$, as shown in Fig. 1c. Such different torsional barriers in the two molecules could significantly influence the molecular crystallinity and self-organization [41-43]. Moreover, as shown in Fig. 1d, the differential scanning calorimetry (DSC) measurement exhibits that the BTR shows a nematic liquid crystalline property. While B1 reveals only one phase transition, without any liquid crystalline property as BTR. Besides, B1 also shows higher transition temperature and transition enthalpy of $279^{\circ} \mathrm{C}$ and $29.3 \mathrm{~J} \mathrm{~g}^{-1}$, which should be ascribed to the increased degree of symmetry in the molecular structure by introducing the benzene unit. The GIWAXS measurements reveal that the molecular orientation is changed from face-on dominant (Fig. 1f, BTR) to edge-on dominant (Fig. 1e, B1) as a consequence of introducing the benzene unit. Furthermore, the B1 displays a stronger $\pi-\pi$ stacking than BTR as confirmed by the $\pi-\pi$ distances, which comes out to be 3.67 and $3.78 \AA$, respectively (Fig. $1 \mathrm{~g}$ ). In addition, BTR and B1 have similar conjugated structures that possess nearly the same energy level alignment (Fig. 2b), similar absorption spectra (Fig. S5, SI), as well as good solubility in CF.

To get a further insight into how to regulate the crystalline properties of a donor compound, as well as its effect on the blend morphology and NFSM-OSC performance, a NF acceptor BO-4Cl (Fig. 2a) was chosen to be blended with B1 and BTR. The NFSM-OSCs were fabricated with a conventional device structure of ITO/PEDOT:PSS/B1:BO-4Cl or BTR:BO-4Cl/PFN-Br/Al. The device optimization details including the various active layer thicknesses, donor/acceptor ratios, and solvent vapor annealing times are summarized in Tables S1-S7. CF and chlorobenzene $(\mathrm{CB})$ were used as the SVA sources to treat the active layers, respectively. The $J-V$ plots of the optimized devices are shown in Fig. 2c, with their corresponding photovoltaic parameters listed in Table 2 . We note that the devices based on these two donor molecules produce open-circuit voltages $\left(V_{\text {oc }}\right)$ of $\sim 0.83 \mathrm{~V}$, which is reasonable in terms of their comparable highest occupied molecular orbital (HOMO) levels which was tested by estimation from the CV measurement (Fig. S6). However, their short-circuit current density $\left(J_{\text {sc }}\right)$ and fill factor (FF) values are different. The devices based on the BTR:BO$4 \mathrm{Cl}$ system produce a $J_{\mathrm{sc}}$ of $18.67 \mathrm{~mA} \mathrm{~cm}^{-2}$, an $\mathrm{FF}$ of 0.67 and a PCE of $10.4 \%$. In comparison, the $\mathrm{B} 1: \mathrm{BO}-4 \mathrm{Cl}$ system exhibits a high $J_{\mathrm{sc}}$ of $25.27 \mathrm{~mA} \mathrm{~cm}^{-2}$, an $\mathrm{FF}$ of 0.73 , and a PCE of $15.3 \%$, outperforming the BTR system under the same treatment conditions. Fig. $2 \mathrm{~d}$ shows the 
Table 2 Detailed photovoltaic parameters of the B1:BO-4Cl-based and BTR:BO-4Cl-based NFSM-OSCs under simulated AM 1.5G (100 mW cm ${ }^{-2}$ ) illumination

\begin{tabular}{|c|c|c|c|c|c|c|c|}
\hline Materials & Treatment & $V_{\mathrm{oc}}(\mathrm{V})^{\mathrm{a}}$ & $J_{\mathrm{sc}}\left(\mathrm{mA} \mathrm{cm}^{-2}\right)^{\mathrm{a}}$ & $\mathrm{FF}^{\mathrm{a}}$ & $\operatorname{PCE}(\%)^{a}$ & $J_{\mathrm{sc}}{ }^{\mathrm{b}}$ & $\left(\mathrm{mA} \mathrm{cm}^{-2}\right)$ \\
\hline \multirow[t]{2}{*}{$\mathrm{B} 1: \mathrm{BO}-4 \mathrm{Cl}$} & CB SVA & $0.83(0.82 \pm 0.01)$ & $25.27(24.81 \pm 0.40)$ & $0.73(0.73 \pm 0.01)$ & $15.3(14.9 \pm 0.2)$ & & 24.56 \\
\hline & CF SVA & $0.82(0.82 \pm 0.01)$ & $24.34(24.05 \pm 0.53)$ & $0.75(0.74 \pm 0.01)$ & $15.0(14.6 \pm 0.3)$ & & 23.78 \\
\hline \multirow[t]{2}{*}{ BTR:BO-4Cl } & CB SVA & $0.83(0.83 \pm 0.01)$ & $18.67(17.91 \pm 0.75)$ & $0.67(0.66 \pm 0.01)$ & $10.4(9.9 \pm 0.5)$ & & 18.15 \\
\hline & CF SVA & $0.83(0.83 \pm 0.01)$ & $18.93(19.01 \pm 0.28)$ & $0.72(0.69 \pm 0.02)$ & $11.3(10.9 \pm 0.3)$ & & 18.54 \\
\hline
\end{tabular}

a) The average parameters were calculated from more than 10 independent devices. b) $J_{\mathrm{sc}}$ was calculated from the integration of the EQE spectrum.

EQE curves of the devices, where although, the same photoresponse region is observed, the response intensity of B1-based devices appears to be much higher (the maximum EQE is $80 \%$ ) than that of BTR:BO-4Cl-based devices. The higher EQE in the whole region indicates the improved charge generation and transport in both the donor and acceptor domains, which may be attributed to the blend morphology synergetic modulation effect, arising from the adjustment of the donor-acceptor pair interaction. For both systems, the corresponding calculated $J_{\mathrm{sc}}$ obtained by the integration of EQE data are all close to the $J_{\mathrm{sc}}$ values from the $J-V$ measurements, with a less than 3\% mismatch. Furthermore, a PCE of $15.1 \%$ has been also certified by the National Institute of Metrology, China (NIM) (Fig. 2e and Fig. S7). To the best of our knowledge, this certified PCE is the highest value reported among NFSM-OSCs. The histograms and corresponding Gaussian distribution of PCE counts for 40 individual $\mathrm{B} 1 \mathrm{BO}-\mathrm{CCl}$-based devices with $\mathrm{CB}$ SVA treatment are shown in Fig. 2f. The significantly enhanced photovoltaic performance of B1-based devices suggests that the increased crystallinity of the donor materials plays a crucial role in designing high-performance NFSM-OSCs.

To unearth the cause of the huge differences in device performances of these two blends, we initially compared the corresponding absorption spectra of their blends as shown in Fig. S8. However, the drastic improvement in the $J_{\mathrm{sc}}$ of the B1-based devices cannot be ascribed to the similar absorption characteristics of the blend films. Hence, the photocurrent analysis was performed to investigate the charge generation, dissociation, and extraction processes. Fig. S9 shows the photocurrent density $\left(J_{\text {ph }}\right.$, the current density under illumination minus the current density in the dark) against the effective voltage ( $V_{\text {eff }}$, the voltage at which $J_{\text {ph }}=0$ minus the applied voltage) of the devices. The exciton dissociation probability $\left(P_{\text {diss }}\right.$, determined by $J_{\mathrm{ph}} / J_{\text {sat }}, J_{\text {sat }}$ denotes the saturation current density and equals to $J_{\text {ph }}$ when $V_{\text {eff }} \geq 2.0 \mathrm{~V}$ ) $[44,45]$ values for B1- and BTR-based devices comes out to be
$97 \%$ and $82 \%$, respectively, under optimal conditions at $V_{\text {eff }}=5 \mathrm{~V}$, which is in accordance with the higher $J_{\mathrm{sc}}$ of B1-based devices. Furthermore, the light-intensity-dependent $J_{\mathrm{sc}}$ measurement was carried out to identify the charge recombination mechanism of these devices. The relationship between $J_{\mathrm{sc}}$ and the illumination intensity $(P)$ can be expressed as $J_{\mathrm{sc}} \propto P^{S}$. As shown in Fig. S10, the corresponding $S$ factors for B1- and BTR-based devices are 0.99 and 0.92 , respectively, indicating that bi-molecular recombination in the B1-based device is negligible [46]. The hole and electron mobilities of the blends were measured by using the space charge limited current (SCLC) method [47,48]. The B1:BO-4Cl blend film with CB SVA treatment exhibits a relatively high hole mobility $\left(\mu_{\mathrm{h}}\right)$ of $2.3 \times 10^{-3} \mathrm{~cm}^{2} \mathrm{~V}^{-1} \mathrm{~s}^{-1}$ and an electron mobility $\left(\mu_{\mathrm{e}}\right)$ of $5.6 \times 10^{-4} \mathrm{~cm}^{2} \mathrm{~V}^{-1} \mathrm{~s}^{-1}$ (Fig. S11). The BTR:BO-4Cl blend film, on the other hand, shows a $\mu_{\mathrm{h}}$ of $1.4 \times 10^{-3} \mathrm{~cm}^{2} \mathrm{~V}^{-1} \mathrm{~s}^{-1}$ and a $\mu_{\mathrm{e}}$ of $4.7 \times 10^{-5} \mathrm{~cm}^{2} \mathrm{~V}^{-1} \mathrm{~s}^{-1}$, respectively. These results indicate that the hole and electron transport is higher and more balanced in the $\mathrm{B} 1$ :BO$4 \mathrm{Cl}$ blends, which explains the improved $\mathrm{FF}$ for corresponding devices.

The morphology of the active layer of the NFSM-OSCs is crucial in determining the photovoltaic performance. To investigate the effect of SVA on the molecular orientation and crystallinity of $\mathrm{B} 1: \mathrm{BO}-4 \mathrm{Cl}$ and BTR:BO- $4 \mathrm{Cl}$ blend films, the GIWAXS measurement was performed. Fig. 3 shows the 2D patterns and corresponding out-ofplane (OOP) and in-plane (IP) curves for the binary blends, with and without CB SVA. Likewise, the scattering data for unitary $\mathrm{B} 1, \mathrm{BTR}, \mathrm{BO}-4 \mathrm{Cl}$ and the corresponding binary blends with CF SVA and their 1D scattering curves are given in Figs S12 and S13. For the unitary B1 films, the (100) peak of B1 located at $0.31 \AA^{-1}$ becomes intense and sharp in both IP and OOP directions (Fig. S12) as a consequence of CF and CB SVA, thus, indicating an enhancement in the crystallinity of the corresponding films due to the SVA treatment. Furthermore, the SVA treatment also alters the molecular orientation of $\mathrm{B} 1$ and leads to a greater face-on orientation 

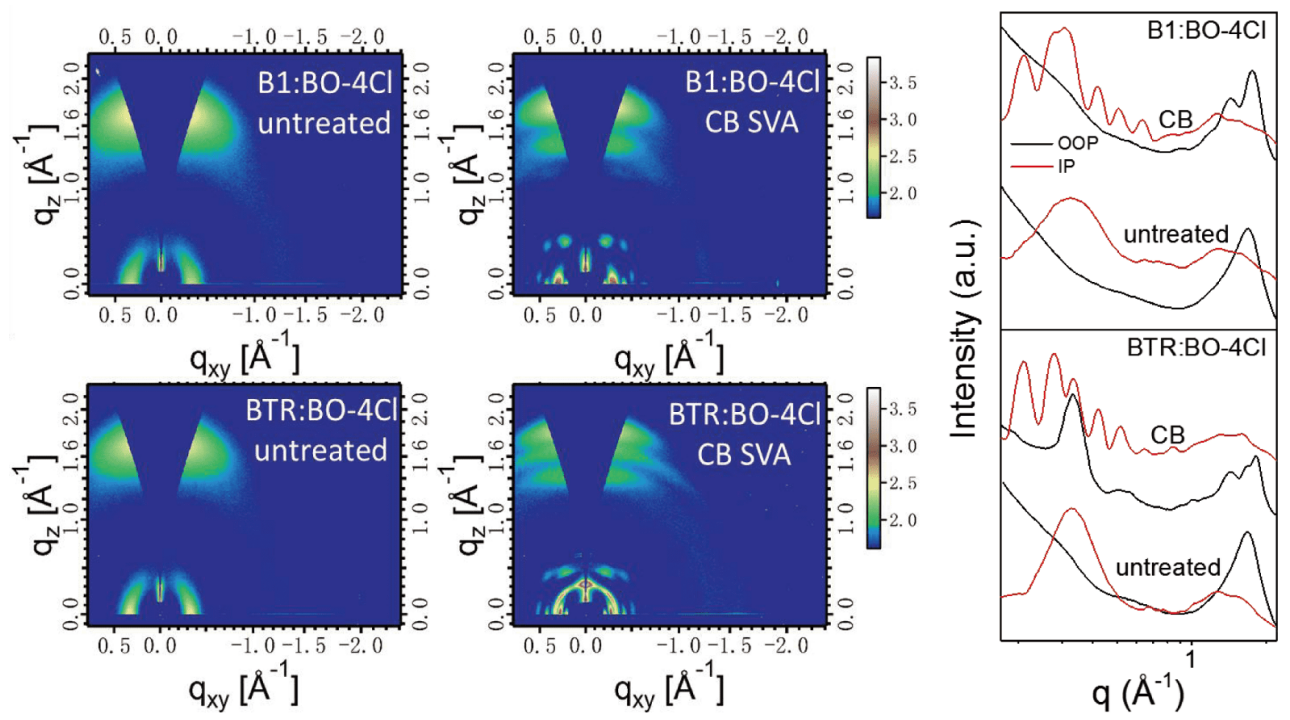

Figure 3 The 2D scattering patterns and corresponding OOP and IP curves of $\mathrm{B} 1: \mathrm{BO}-4 \mathrm{Cl}$ and $\mathrm{BTR}: \mathrm{BO}-4 \mathrm{Cl}$ blend films.

in the corresponding devices. However, for the unitary BTR films, the scattering peaks nearly maintain the same intensities and face-on orientation. Since the pristine BTR exhibits good crystallinity and face-on orientation, the SVA treatment has a negligible influence on its crystallinity (Fig. S12). Likewise, for the unitary $\mathrm{BO}-4 \mathrm{Cl}$ films, the $\pi-\pi$ stacking peak at $1.72 \AA^{-1}$, corresponding to a $\pi-\pi$ distance of $3.64 \AA$, becomes increasingly sharp with CF and CB SVA. The correlation lengths of the $\pi-\pi$ stacking, calculated by the Scherrer equation [49], comes out to be 16.7, 25.6 and $28.7 \AA$ for the pristine, CF-treated and CBtreated films, respectively. Compared with the GIWAXS data shown in Fig. 3, the solvent-annealed B1:BO-4Cl blend film shows an improved donor and acceptor crystallinity, as well as a dominant face-on orientation (Fig. 3). Similarly, from the 2D patterns and 1D curves, the (100) scattering peak of $\mathrm{B} 1$, located at $0.31 \AA^{-1}$, is absent in the OOP direction but present in the IP direction. The face-on ratio is $94 \%$ in the blend film, while it is only $2 \%$ in the pristine B1 film (Fig. S14) [50]. This indicates that the $\mathrm{B} 1$ donor is now exhibiting a face-on orientation within the binary blend films, which further specifies that the molecular orientation of B1 is significantly affected and induced to a face-on orientation by $\mathrm{BO}-4 \mathrm{Cl}$. That might be due to the fact that $\mathrm{B} 1$ and $\mathrm{BO}-$ $4 \mathrm{Cl}$ have strong interaction and similar $\pi-\pi$ stacking distances (3.67 vs. $3.64 \AA$ ). On the other hand, for the BTR:BO-4Cl blend film, the (100) scattering peak of BTR is present in both IP and OOP directions, similar to the pristine film (Fig. 1f). The face-on ratios almost keep constant, which are $18.4 \%$ and $18.3 \%$ in blend film and pristine film, respectively. Likewise, the $2 \mathrm{D}$ patterns of BTR:BO-4Cl blend films can simply be seen as the addition of pristine $\mathrm{BTR}$ and $\mathrm{BO}-4 \mathrm{Cl}$ in the same film, as both BTR and $\mathrm{BO}-4 \mathrm{Cl}$ behave individually, and thus, highlighting their weak interaction.

To investigate the morphological characteristics of the photoactive layers, the surface and bulk morphologies of the blend films were obtained using AFM and TEM, respectively (Fig. 4). Fig. $4 \mathrm{~b}$ and d display the AFM phase images of the two active layers with CB SVA treatments, whereby, it can be seen that both phase separation and surface roughness of the $\mathrm{B} 1: \mathrm{BO}-4 \mathrm{Cl}$ films are higher than those of BTR:BO-4Cl films under the optimal conditions. The $\mathrm{B} 1: \mathrm{BO}-4 \mathrm{Cl}$ blend film exhibits a root-mean-square (RMS) roughness of $2.13 \mathrm{~nm}$, while BTR:BO-4Cl system gives a value of $1.04 \mathrm{~nm}$. Similarly, the TEM images (Fig. 4c, f) also depict that the internal morphological characteristics of blend films for these two donor compounds are evidently different. The $\mathrm{B} 1: \mathrm{BO}-4 \mathrm{Cl}$ blend demonstrates a fibrous morphology with small-size aggregation, whereas, the less-defined domains are observed in the BTR:BO-4Cl blends, which could cause the suppressed exciton dissociation, as discussed previously. Likewise, the $\mathrm{B} 1: \mathrm{BO}-4 \mathrm{Cl}$ blend reveals enhanced interfacial phase separation, that can effectively promote exciton dissociation, charge transfer, as well as reduce charge recombination, and ultimately contribute to a boost in $J_{\mathrm{sc}}$ and $\mathrm{FF}$ in the corresponding devices.

\section{CONCLUSION}

In summary, we designed and synthesized a new 2D- 

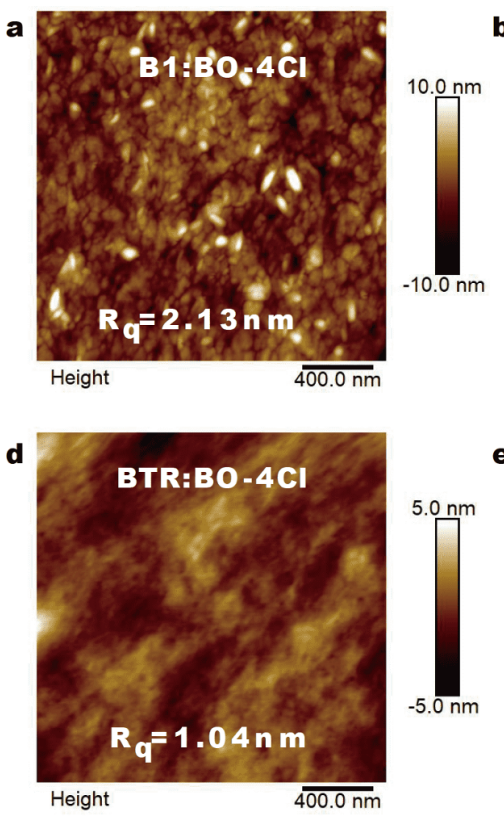
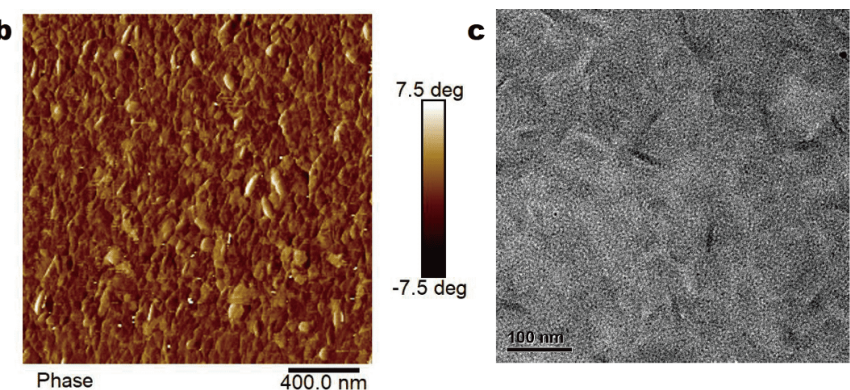

e
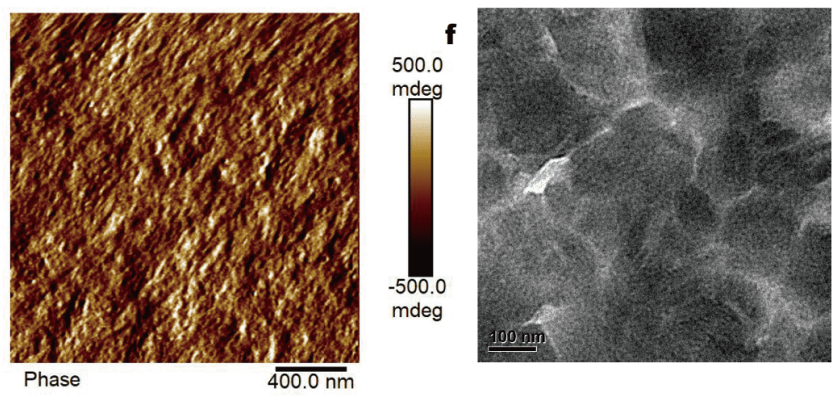

Figure 4 The AFM height images (a, d), phase images (b, e), and TEM images (c, f) of B1:BO-4Cl- and BTR:BO-4Cl-based blend films with CB SVA treatment.

conjugated donor, $\mathrm{B} 1$, that comprised of phenyl-substituted BDT central units, exhibited higher rotational barrier, improved crystalline properties, increased $\pi-\pi$ stacking, as well as significantly enhanced photovoltaic performance in comparison with those of its corresponding thiophene-substituted BDT-based compound, BTR. In addition, a strong interaction between the donor and the acceptor in the B1-based blend films was observed, indicating that the synergistic optimization of donor-acceptor blend morphology could be achieved by tuning the symmetry of the donor material. The NFSMOSCs obtained by pairing $\mathrm{B} 1$ with an NF acceptor (BO$4 \mathrm{Cl}$ ) achieve a high PCE of $15.3 \%$ (certified PCE 15.1\%) with a high $J_{\mathrm{sc}}$ of $25.27 \mathrm{~mA} \mathrm{~cm} \mathrm{c}^{-2}$ and a high $\mathrm{FF}$ of 0.73 , which is the highest PCE for NFSM-OSCs reported so far, while the BTR-based device could only manage a PCE of $10.4 \%$. Our results reveal that increasing the crystalline properties of donor molecule by simply modulating the symmetry of the conjugated side group contributes to the synergistic optimization of donor-acceptor blend morphology, and therefore avails to realize high-performance NFSM-OSCs.

Received 7 January 2020; accepted 14 February 2020; published online 18 March 2020

1 Yuan J, Zhang Y, Zhou L, et al. Single-junction organic solar cell with over $15 \%$ efficiency using fused-ring acceptor with electrondeficient core. Joule, 2019, 3: 1140-1151
2 Lin Y, Adilbekova B, Firdaus Y, et al. 17\% Efficient organic solar cells based on liquid exfoliated $\mathrm{WS}_{2}$ as a replacement for PEDOT: PSS. Adv Mater, 2019, 31: 1902965

3 Cui Y, Yao H, Hong L, et al. 17\% Efficiency organic photovoltaic cell with superior processability. Natl Sci Rev, 2019, https://doi.org/ 10.1093/nsr/nwz200

4 Collins SD, Ran NA, Heiber MC, et al. Small is powerful: recent progress in solution-processed small molecule solar cells. Adv Energy Mater, 2017, 7: 1602242

5 Chen Y, Wan X, Long G. High performance photovoltaic applications using solution-processed small molecules. Acc Chem Res, 2013, 46: 2645-2655

$6 \mathrm{He} \mathrm{C}$, Hou J. Advances in solution-processed all-small-molecule organic solar cells with non-fullerene electron acceptors. Acta Phys Chim Sin, 2018, 34: 1202-1210

7 Mishra A, Bäuerle P. Small molecule organic semiconductors on the move: promises for future solar energy technology. Angew Chem Int Ed, 2012, 51: 2020-2067

8 Lin Y, Zhan X. Non-fullerene acceptors for organic photovoltaics: an emerging horizon. Mater Horiz, 2014, 1: 470-488

9 Qian D, Ye L, Zhang M, et al. Design, application, and morphology study of a new photovoltaic polymer with strong aggregation in solution state. Macromolecules, 2012, 45: 9611-9617

10 Li G, Shrotriya V, Huang J, et al. High-efficiency solution processable polymer photovoltaic cells by self-organization of polymer blends. Nat Mater, 2005, 4: 864-868

11 Zhang $\mathrm{T}$, An $\mathrm{C}$, Ma K, et al. Increased conjugated backbone twisting to improve carbonylated-functionalized polymer photovoltaic performance. Org Chem Front, 2020, 7: 261-266

12 Yang L, Zhang S, He C, et al. Modulating molecular orientation enables efficient nonfullerene small-molecule organic solar cells. Chem Mater, 2018, 30: 2129-2134

13 Wan J, Xu X, Zhang G, et al. Highly efficient halogen-free solvent processed small-molecule organic solar cells enabled by material 
design and device engineering. Energy Environ Sci, 2017, 10: 17391745

14 Ji Z, Xu X, Zhang G, et al. Synergistic effect of halogenation on molecular energy level and photovoltaic performance modulations of highly efficient small molecular materials. Nano Energy, 2017, 40: $214-223$

15 Piradi V, Xu X, Wang Z, et al. Panchromatic ternary organic solar cells with porphyrin dimers and absorption-complementary benzodithiophene-based small molecules. ACS Appl Mater Interfaces, 2019, 11: 6283-6291

16 Gao K, Jo SB, Shi X, et al. Over 12\% efficiency nonfullerene allsmall-molecule organic solar cells with sequentially evolved multilength scale morphologies. Adv Mater, 2019, 31: 1807842

$17 \mathrm{Wu} \mathrm{H}$, Fan $\mathrm{H}, \mathrm{Xu} \mathrm{S}$, et al. Isomery-dependent miscibility enables high-performance all-small-molecule solar cells. Small, 2019, 15: 1804271

18 Guo J, Bin H, Wang W, et al. All-small molecule solar cells based on donor molecule optimization with highly enhanced efficiency and stability. J Mater Chem A, 2018, 6: 15675-15683

19 Zhou Z, Xu S, Song J, et al. High-efficiency small-molecule ternary solar cells with a hierarchical morphology enabled by synergizing fullerene and non-fullerene acceptors. Nat Energy, 2018, 3: 952959

20 Zhang H, Wang X, Yang L, et al. Improved domain size and purity enables efficient all-small-molecule ternary solar cells. Adv Mater, 2017, 29: 1703777

21 Huo Y, Gong XT, Lau TK, et al. Dual-accepting-unit design of donor material for all-small-molecule organic solar cells with efficiency approaching 11\%. Chem Mater, 2018, 30: 8661-8668

22 Yang L, Zhang S, He C, et al. New wide band gap donor for efficient fullerene-free all-small-molecule organic solar cells. J Am Chem Soc, 2017, 139: 1958-1966

23 Zhao W, Li S, Yao H, et al. Molecular optimization enables over $13 \%$ efficiency in organic solar cells. J Am Chem Soc, 2017, 139: 7148-7151

24 Huo Y, Zhang HL, Zhan X. Nonfullerene all-small-molecule organic solar cells. ACS Energy Lett, 2019, 4: 1241-1250

25 Zhang J, Tan HS, Guo X, et al. Material insights and challenges for non-fullerene organic solar cells based on small molecular acceptors. Nat Energy, 2018, 3: 720-731

26 Nielsen CB, Holliday S, Chen HY, et al. Non-fullerene electron acceptors for use in organic solar cells. Acc Chem Res, 2015, 48: 2803-2812

27 Zhou R, Jiang Z, Yang C, et al. All-small-molecule organic solar cells with over $14 \%$ efficiency by optimizing hierarchical morphologies. Nat Commun, 2019, 10: 5393

28 Chen H, Hu D, Yang Q, et al. All-small-molecule organic solar cells with an ordered liquid crystalline donor. Joule, 2019, 3: 30343047

29 Yue Q, Wu H, Zhou Z, et al. 13.7\% Efficiency small-molecule solar cells enabled by a combination of material and morphology optimization. Adv Mater, 2019, 31: 1904283

30 Ge J, Xie L, Peng R, et al. 13.34\% Efficiency non-fullerene allsmall-molecule organic solar cells enabled by modulating the crystallinity of donors via a fluorination strategy. Angew Chem Int Ed, 2020, 59: 2808-2815

31 Beaujuge PM, Fréchet JMJ. Molecular design and ordering effects in $\pi$-functional materials for transistor and solar cell applications. J Am Chem Soc, 2011, 133: 20009-20029

32 Zhan C, Yao J. More than conformational "twisting" or "copla- narity": molecular strategies for designing high-efficiency nonfullerene organic solar cells. Chem Mater, 2016, 28: 1948-1964

33 Kang H, Kim KH, Choi J, et al. High-performance all-polymer solar cells based on face-on stacked polymer blends with low interfacial tension. ACS Macro Lett, 2014, 3: 1009-1014

34 Feng S, Zhang C', Bi Z, et al. Controlling molecular packing and orientation via constructing a ladder-type electron acceptor with asymmetric substituents for thick-film nonfullerene solar cells. ACS Appl Mater Interfaces, 2019, 11: 3098-3106

35 Yao H, Ye L, Zhang $\mathrm{H}$, et al. Molecular design of benzodithiophene-based organic photovoltaic materials. Chem Rev, 2016, 116: 7397-7457

36 Aldrich TJ, Leonardi MJ, Dudnik AS, et al. Enhanced fill factor through chalcogen side-chain manipulation in small-molecule photovoltaics. ACS Energy Lett, 2017, 2: 2415-2421

37 Jiang JM, Lin HK, Lin YC, et al. Side chain structure affects the photovoltaic performance of two-dimensional conjugated polymers. Macromolecules, 2013, 47: 70-78

38 Sun K, Xiao Z, Lu S, et al. A molecular nematic liquid crystalline material for high-performance organic photovoltaics. Nat Commun, 2015, 6: 6013

39 Liu Y, Chen CC, Hong Z, et al. Solution-processed small-molecule solar cells: breaking the $10 \%$ power conversion efficiency. Sci Rep, 2013, 3: 3356

40 Kan B, Zhang Q, Li M, et al. Solution-processed organic solar cells based on dialkylthiol-substituted benzodithiophene unit with efficiency near 10\%. J Am Chem Soc, 2014, 136: 15529-15532

41 Zhang S, Qin Y, Uddin MA, et al. A fluorinated polythiophene derivative with stabilized backbone conformation for highly efficient fullerene and non-fullerene polymer solar cells. Macromolecules, 2016, 49: 2993-3000

42 Zhang S, Yang B, Liu D, et al. Correlations among chemical structure, backbone conformation, and morphology in two highly efficient photovoltaic polymer materials. Macromolecules, 2016, 49: $120-126$

43 Liu D, Yang L, Wu Y, et al. Tunable electron donating and accepting properties achieved by modulating the steric hindrance of side chains in A-D-A small-molecule photovoltaic materials. Chem Mater, 2018, 30: 619-628

44 Kyaw AKK, Wang DH, Wynands D, et al. Improved light harvesting and improved efficiency by insertion of an optical spacer $(\mathrm{ZnO})$ in solution-processed small-molecule solar cells. Nano Lett, 2013, 13: 3796-3801

45 Mihailetchi VD, Koster LJA, Hummelen JC, et al. Photocurrent generation in polymer-fullerene bulk heterojunctions. Phys Rev Lett, 2004, 93: 216601

46 Cowan SR, Roy A, Heeger AJ. Recombination in polymer-fullerene bulk heterojunction solar cells. Phys Rev B, 2010, 82: 245207

47 Vohra V, Kawashima K, Kakara T, et al. Efficient inverted polymer solar cells employing favourable molecular orientation. Nat Photon, 2015, 9: 403-408

48 Blom PWM, de Jong MJM, Vleggaar JJM. Electron and hole transport in poly(p-phenylene vinylene) devices. Appl Phys Lett, 1996, 68: 3308-3310

49 Smilgies DM. Scherrer grain-size analysis adapted to grazing-incidence scattering with area detectors. J Appl Crystlogr, 2009, 42: 1030-1034

50 Rivnay J, Mannsfeld SCB, Miller CE, et al. Quantitative determination of organic semiconductor microstructure from the molecular to device scale. Chem Rev, 2012, 112: 5488-5519 
Acknowledgements This work was financially supported by the Basic and Applied Basic Research Major Program of Guangdong Province (2019B030302007), and the National Natural Science Foundation of China $(51873217,21734008,51703228,51961135103,51773047$ and 51903239).

Author contributions Hou J and $\mathrm{He} \mathrm{C}$ conceived and designed the experiments; $\mathrm{An} \mathrm{C}$ and $\mathrm{Ma} \mathrm{K}$ synthesized and characterized the molecules; Zhang J, Tang Y and Ma W performed the GIWAXS measurements; Qin J fabricated the devices; Yang Y carried out the TEM measurements; All authors contributed to the general discussion.

Conflict of interest The authors declare no conflict of interest.

Supplementary information Experimental details and supporting data are available in the online version of the paper.

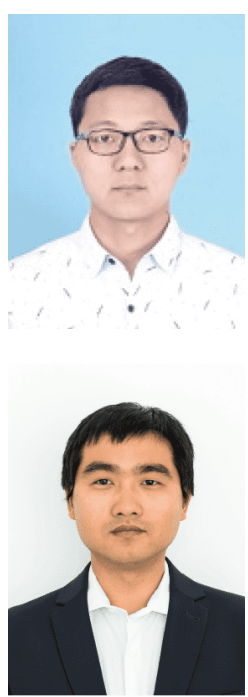

Jinzhao Qin received his BSc degree in the Department of Polymer Science and Engineering from the University of Science and Technology of China. Now he is a $\mathrm{PhD}$ candidate in Prof. Jianhui Hou's group in the Institute of Chemistry, Chinese Academy of Sciences (ICCAS). His current research focuses on organic photovoltaic devices.

Cunbin An received his $\mathrm{PhD}$ degree from Max Planck Institute for Polymer Research in 2015. After one-year postdoctoral research in the same group, he joined ICCAS as an assistant professor. His current research focuses on developing conjugated materials for organic photovoltaics.

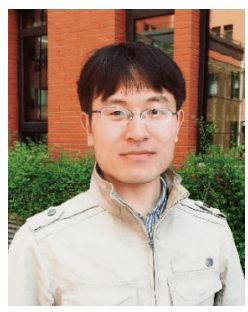

Jianqi Zhang received his $\mathrm{PhD}$ degree in polymer physics and chemistry at Changchun Institute of Applied Chemistry, Chinese Academy of sciences in 2010. After that, he did postdoctoral research at Technische Universität München (TUM). He has been an associate professor at the National Center of Nanoscience and Technology (NCNST) since 2017. His research interests focus on using wide- and small-angle X-ray scattering to study complex structure-performance relationships of photovoltaic systems.

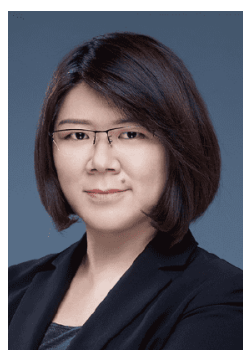

Chang He has been a professor at ICCAS since 2019. She graduated with a BSc degree in 1997 from Xi'an Jiaotong University. She obtained her $\mathrm{PhD}$ degree in physical chemistry from ICCAS in 2007. Her research interests focus on solutionprocessible small molecule photovoltaic materials and the related devices.

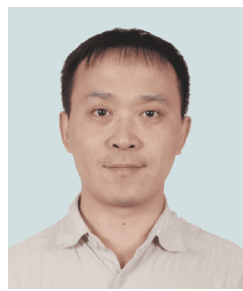

Jianhui Hou received his $\mathrm{PhD}$ degree from ICCAS in 2006. Then he worked as a postdoctoral researcher in Prof. Yang Yang's group at the University of California at Los Angeles. $\mathrm{He}$ joined the Solarmer Energy Inc. (USA) in 2008 as a team leader of research department. He became a full professor of ICCAS since 2010, and his research focuses on the design, synthesis and application of the organic/polymer photovoltaic materials.

\section{给体对称性苯基修饰实现效率高达 $15.3 \%$ 的全小} 分子有机太阳能电池

秦金㻇 ${ }^{1,2}$, 安存涁 ${ }^{*}$, 张建齐 ${ }^{2,3^{*}}$, 马康桥 ${ }^{1}$, 杨扬 ${ }^{2,3}$, 张涛 ${ }^{1}$,

李称蒜, 鲜开虎 ${ }^{1,2}$, 崔勇 ${ }^{1}$, 唐亚兵 ${ }^{5}$, 马伟 ${ }^{5}$, 姚惠峰 ${ }^{1}$, 张少青 ${ }^{4}$, 许博为 ${ }^{1}$, 何畅 ${ }^{1 *}$, 侯剑辉 ${ }^{1,2^{*}}$

摘要 太阳能电池结构中给体和受体的各向异性使得调制优化共 混薄膜的形貌面临巨大挑战, 因而使得非富勒烯全小分子太阳能 电池很难实现高效率. 因此, 开发一种简便的分子设计策略有效地 调节光活性材料的结晶特性，从而实现对共混形貌的协同调制变 得至关重要. 在本工作中, 我们设计合成了侧基苯基取代的新给体 分子 $\mathrm{B} 1$. 与噻吩侧基取代给体小分子 $\mathrm{BTR}$ 相比, 侧基对称苯基取代 的B1具有更强的结晶性. B1 与非富勒烯受体 BO- $4 \mathrm{Cl}$ 共混制备全小 分子器件, GIWAXS测试发现在共混膜中 B1 的分子取向被受体分 子 $\mathrm{BO}-4 \mathrm{Cl}$ 显著诱导, $\mathrm{B} 1$ 优势分子取向由单纯膜中的edge-on转变为 共混膜中的face-on, 表明 $\mathrm{B} 1$ 与 $\mathrm{BO}-4 \mathrm{Cl}$ 之间存在更强的相互作用. 基 于 $\mathrm{B} 1: \mathrm{BO}-4 \mathrm{Cl}$ 的器件获得了 $15.3 \%$ 的能量转换效率, 经中国计量科 学研究院(NIM)认证为 $15.1 \%$. 本工作结果提供了一种简单而有效 的策略来改善给体分子的结晶性能, 并实现活性层形貌的协同优 化, 从而获得了全小分子器件能量转化效率的突破. 